\title{
An Analysis of Diversity in Freshwater Mussels (Bivalvia: Unionidae) of the Cuyahoga and Rocky River Watersheds (Ohio, USA) Based on the 16S rRNA Gene
}

\author{
Robert A. Krebs \\ Cleveland State University, r.krebs@csuohio.edu \\ Roxana N. Vlasceanu \\ Cleveland State University \\ Michael J.S. Tevesz

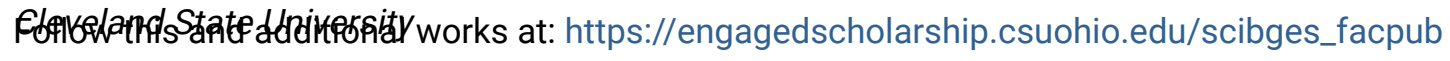 \\ Part of the Biodiversity Commons, Biology Commons, and the Genetics Commons \\ How does access to this work benefit you? Let us know!

\section{Publisher's Statement} \\ NOTICE: this is the author's version of a work that was accepted for publication in Journal of \\ Great Lakes Research. Changes resulting from the publishing process, such as peer review, \\ editing, corrections, structural formatting, and other quality control mechanisms may not be \\ reflected in this document. Changes may have been made to this work since it was submitted \\ for publication. A definitive version was subsequently published in Journal of Great Lakes \\ Research, 29, 2, (2003) DOI 10.1016/S0380-1330(03)70436-5
}

\section{Recommended Citation}

Krebs RA, Vlasceanu RN, Tevesz MJS. 2003. An analysis of diversity in freshwater mussels (bivalvia: Unionidae) of the cuyahoga and rocky river watersheds (ohio, USA) based on the 16S rRNA gene. J Great Lakes Res 29(2):307-16. 


\title{
An Analysis of Diversity in Freshwater Mussels (Bivalvia: Unionidae) of the Cuyahoga and Rocky River Watersheds (Ohio, USA) Based on the 16S rRNA Gene
}

\author{
Robert A. Krebs*, Roxana N. Vlasceanu, and Michael J. S. Tevesz \\ Department of Biological \\ Geological and Environmental Sciences \\ Cleveland State University \\ 2121 Euclid Ave. \\ Cleveland, Ohio 44115
}

\begin{abstract}
The continued loss of freshwater unionid mussel species in the Great Lakes region, and particularly from Lake Erie, raises the question of how much phylogenetic and genetic variation remain in the watershed. The introduction of molecular markers into population biology offers one reproducible technique for assessing this variation. A fragment of the $16 S$ rRNA gene of mitochondrial DNA has previously been used to infer phylogenetic relationships in the family Unionidae. Therefore, we reanalyzed these published molecular data with the addition of 12 species from the Cuyahoga and Rocky rivers in northeast Ohio. Both rivers drain to Lake Erie. The species assessed were Pyganodon grandis, Lasmigona complanata, Lasmigona compressa, Lampsilis radiata luteola, Fusconaia flava, Potamilus alatus, Strophitus undulatus, and Toxolasma parvus, for which published data were unavailable, and northern specimens of four wide ranging species, Lasmigona costata, Leptodea fragilis, Utterbackia imbecillis, and Quadrula quadrula. The resulting phylogenetic tree remained consistent with the accepted major taxonomic divisions in the Unionidae, and it indicates that these rivers still contain a phylogenetically diverse assemblage. However, the most abundant species all are members of the Anodontinae. Intraspecific variation in these unionid species was low, even where results were compared to published sequences on individuals from distant watersheds. One exception was a unique haplotype of $\mathrm{Q}$. quadrula that differed at more base sites than is generally found for many congeneric species.
\end{abstract}

INDEX WORDS: Conservation, evolution, genetics, population, Unionidae.

\section{INTRODUCTION}

Freshwater mussels in Ohio (Bivalvia: Unionidae), which may have numbered as many as 80 species in the recent past, continue to decline in both abundance and geographic range (Watters 1995). The greatest loss has been the entire habitat of western Lake Erie, originally home to 34 species (La Rocque 1967), all of which were extirpated locally following invasion of the lake by the zebra mussel, Dreissena polymorpha. The refuge for these populations now becomes the rivers and wetlands surrounding the lake. A big problem with respect to conserving the unionid communities of these streams is that they have experienced dramatic faunal shifts since late prehistory (Tevesz et

*Corresponding author. E-mail: r.krebs@csuohio.edu al. 2002), and extant populations are largely unconnected.

Therefore, we now propose a genetic analysis of the species present within the northeastern Ohio rivers. We begin with a study of variation in the Cuyahoga and Rocky rivers, which have been heavily impacted by urbanization at their river mouths. The Cuyahoga River arises $30 \mathrm{~km}$ east of Cleveland, Ohio, flows southward to Akron, and then northwest to empty into Lake Erie at the harbor in downtown Cleveland. The Rocky River enters Lake Erie only about $10 \mathrm{~km}$ to the west of the Cuyahoga after draining much of the near western suburbs of Cleveland. The unionid fauna of the Cuyahoga watershed were recently described by Smith et al. (2002) and Tevesz et al. (2002), and like many of the Canadian rivers that empty into Lake Erie, mus- 
sel species in the Anodontinae continue to increase their representation in the Cuyahoga River fauna, probably because these species better tolerate openness following deforestation (Metcalfe-Smith et al. 2000). No survey of the Rocky River has been published.

Molecular genetic information has proven to be valuable to clarify loss of genetic variation and to better understand unionid systematics where distantly related species often share many of the same morphological characteristics (Lydeard and Roe 1998). Furthermore, environmental variation can induce several kinds of changes in shell shape and thickness (Tevesz and Carter 1980, Mulvey et al. 1998) that can confound identification based on morphology. Mitochondrial DNA genes are among the best for determining relationships among closely related species. The mitochondrial DNA genome represents a complex linkage group composed of approximately 37 genes inherited normally as a single unit, without recombination (Boore 1999; but see Ladoukakis and Zouros 2001). Differences among lineages of mitochondrial ribosomal genes are restricted to independent mutational events, and the rates of mutation fixation in the these genes may be higher than those for their equivalent nuclear counterpart genes (Hillis et al. 1996, Skibinski et al. 1999). Therefore, these sequences are especially useful for determining generic and specific level relationships in molluscs (Lydeard et al. 1998, Stepien et al. 1999, Canapa et al. 2000). Moreover, an improved taxonomic key based on mitochondrial genes may provide a starting point to determine the taxonomic status of species with wide-spread distributions. Without clarifying phylogenetic relationships and geographic variation, unionids, which as a group are the most imperiled animals in North America (Stein and Flack 1997), cannot be evaluated accurately for protection at local levels.

In this study, we advanced a sequence database assembled by Lydeard et al. (1996) which provided information useful in interpreting relationships among unionids. They compared sequence data for a $5^{\prime}$-fragment of the mitochondrial 16S rRNA gene in 26 species from 20 genera. Their study provides valuable background for other investigations of the systematic and genetic variability among the unionids present in a given watershed. Our data extended the taxonomic use of the 16S rRNA gene for Unionids in two ways, (1) by adding several genera not previously included, and (2) by testing the effect of intraspecific variation on the resulting phy- logeny. The latter analysis is important, even though limited by collection restrictions on these protected species, because many of these unionids are wide ranging (Mulvey et al. 1998).

\section{MATERIALS AND METHODS}

\section{Sequence Procurement and Alignment}

We sequenced a fragment of the $16 \mathrm{~S}$ rRNA mtDNA gene from 41 unionids, which composed 12 different species (Genbank accession numbers AY238480- AY238491). We combined these data with 32 sequences from Lydeard et al. (1996), available in GenBank. Our sequences completely overlapped the published sequences. Although the region separated by our primers averaged $500 \mathrm{bp}$, only the central $400 \mathrm{bp}$ could be used for a complete analysis of all species. Together these data represent 25 of 48 genera of the North American unionids, but lack specimens of only four genera, Epioblasma, Obovaria, Quincuncina, and Truncilla, that contain more than two species (Williams et al. 1993).

\section{Specimen Collection}

Mussels were collected from a variety of sites (Fig. 1) within the Cuyahoga River and Rocky

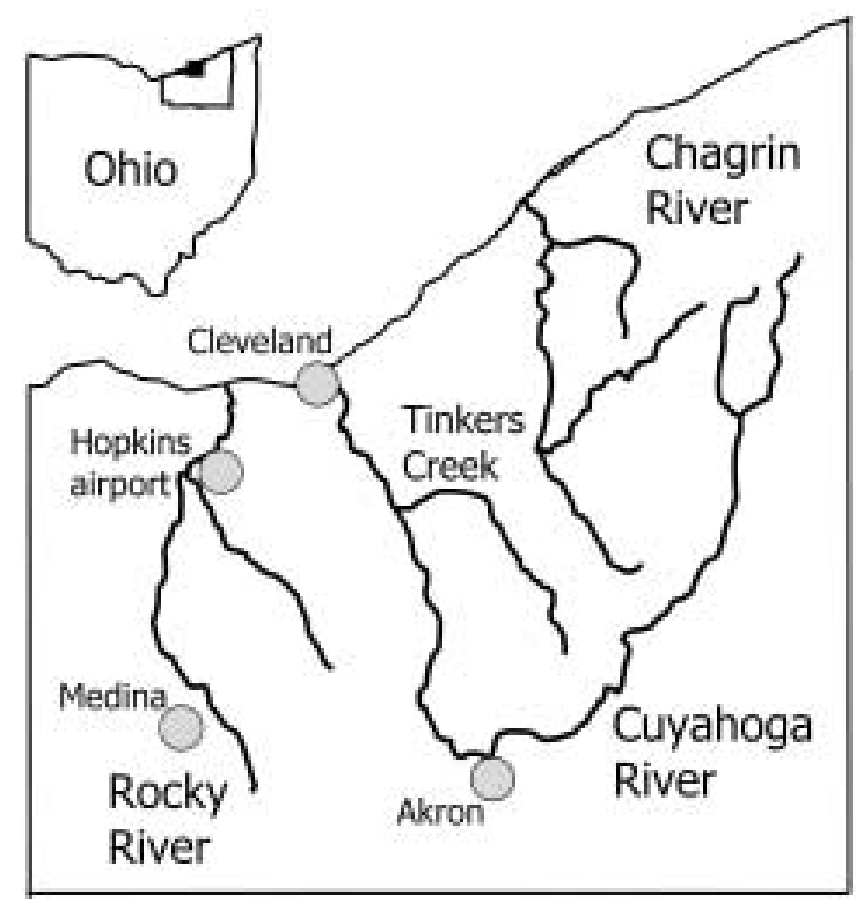

FIG. 1. Location of the Cuyahoga and Rocky Rivers, which flow into Lake Erie in northeast Ohio. 
River watersheds (numbers indicate sample size): from Tinkers Creek, Pyganodon grandis (7), Lasmigona costata (2), L. compressa (2), and Fusconaia flava (2); from the west branch of the Cuyahoga, Pyganodon grandis (4), Lampsilis radiata luteola (2), Lasmigona complanata (2), L. costata (1), and L. compressa (1); and from the Cuyahoga Valley National Park, the Ohio Canal, Pyganodon grandis (3) and Toxolasma parvus (1), Kendall Lake, Utterbackia imbecillis (1) and Horseshoe Lake, Pyganodon grandis (1); from the Rocky River, Pyganodon grandis (2), Lasmigona costata (3), L. compressa (3), Lampsilis radiata luteola (2), Leptodea fragilis (1), Potamilus alatus (1), Strophitus undulatus (1), and Quadrula quadrula (1). The small populations of mussels in these rivers restrict the number available for sampling. Mussels were brought to the laboratory alive, tissue was surgically removed and placed in ice cold $70 \%$ ethanol, and it was stored at $-20^{\circ} \mathrm{C}$ until use.

\section{Extraction of DNA}

We isolated DNA from the adductor muscle or in some specimens from gonadal tissue (females only) by a modified insect grinding protocol (Greg Spicer and Suzanne Pass, SFSU, unpublished). Unionids possess both a male-inherited form of mitochondria as well as the standard female-inherited form, as seen in other bivalves (Ladoukakis and Zouros 2001), but the male form is restricted to gonadal tissue in the Unionidae (Hoeh et al. 1996, Liu et al. 1996). Between 2-4 mg of tissue was suspended in $500 \mu \mathrm{L}$ of grinding solution: $100 \mathrm{mM}$ EDTA, 10 $\mathrm{mM}$ Tris $\mathrm{pH} 8.0,1 \% \mathrm{SDS}$, and $0.4 \mathrm{mg} / \mathrm{mL}$ proteinase $\mathrm{K}$. The tissue was subsequently homogenized with a sterile pestle and incubated at $65^{\circ} \mathrm{C}$ for $1 \mathrm{~h}$. Following incubation, an equal volume of equilibrated phenol was added to the homogenate, the sample was vortexed 1 minute and centrifuged 5 minutes $(13,000 \mathrm{~g})$. The supernatant was transferred to a new tube to which we added an equal volume of chloroform. Again the sample was vortexed, centrifuged, the resultant supernatant transferred, and cleaned a second time with chloroform. After the final transfer of the supernatant, two volumes of ice-cold $100 \%$ ethanol were added to precipitate the DNA, and the sample was cooled $\left(-20^{\circ} \mathrm{C}\right)$ overnight. The next day, the DNA was centrifuged for 5 minutes, the supernatant was discarded, the pellet dried in a vacuum for 20 minutes, and finally re-suspended in $300 \mu \mathrm{L}$ of $1 \mathrm{X}$ TE buffer, $\mathrm{pH} 7.0$ (Palumbi 1997).

\section{PCR Analysis}

The universal primers 16Sar-5' (CGCCTGTTTAACAAAAACAT) and $16 \mathrm{Sbr}-3^{\prime}$ (CCGGTTT GAACTCAGATCATGT) that were optimized for insect use (Palumbi 1997) primed the synthesis of approximately 500 base pairs (bp) of $16 \mathrm{~S}$ mtDNA in unionid mussels. All PCR reactions were carried out in $50 \mu \mathrm{L}$ volumes, consisting of $5 \mu \mathrm{L}$ buffer $\mathrm{A}$ (Fisher Scientific), $5 \mu \mathrm{L}$ dNTPs $(10 \mathrm{mM}), 5 \mu \mathrm{L}$ of each primer $(2.5 \mathrm{mM})$, and generally $10 \mu \mathrm{L}(0.1 \mathrm{M})$ $\mathrm{Mg} 2+$ cofactor and deionized water to a total volume of $48 \mu \mathrm{L}$. To this reaction mix was added 0.4 $\mu \mathrm{L} \mathrm{Taq}$ polymerase before transferring to $2 \mu \mathrm{L}$ template DNA. The reactions were amplified in a PE2400 thermal cycler set at 35 cycles: an initial denaturation phase required $5 \mathrm{~min}$ at $94^{\circ} \mathrm{C}$, with all subsequent denaturation bouts of only $30 \mathrm{sec}$. Annealing phase also was set for $30 \mathrm{sec}$, but temperatures varied by species, from $46^{\circ} \mathrm{C}$ to $50^{\circ} \mathrm{C}$. Extension occurred at $72^{\circ} \mathrm{C}$, for $30 \mathrm{sec}$.

After amplification, primer sequences were removed by a polyethylene glycol (PEG) density centrifugation procedure. First we added $15 \mu \mathrm{L}$ of a $20 \%$ PEG and $2.5 \mathrm{M} \mathrm{NaCl}$ solution to $25 \mu \mathrm{L}$ of PCR product. The sample was vortexed briefly, incubated at $37^{\circ} \mathrm{C}$ for 15 minutes, and centrifuged at $12,000 \mathrm{~g}$ for 25 minutes. The supernatant was discarded and the pellet (often not visible) was washed with $25 \mu \mathrm{L}$ of fresh $80 \%$ ethanol. The sample was again centrifuged for 5 minutes, the supernatant discarded, and the pellet vacuum dried for $20 \mathrm{~min}$ utes. Resuspension in $18 \mu \mathrm{L}$ of PCR water completed the procedure after which samples were delivered to Cleveland Genomics for sequencing, or for later samples, to the Cleveland State University sequencing facility. All samples were sequenced in both directions.

\section{Sequence Analysis}

All mitochondrial 16S rRNA sequences were entered into ClustalV, a package of multiple alignment programs. FASTA format was used for sequence input. Two gap penalties were offered: "fixed"for opening up a gap; "floating"-for extending a gap. The penalty options used for both was 10 (a medium value). Higher values could reduce the sequence length, but they markedly increased tree lengths. DNA transversions were (by program de- 
fault) weighed more strongly than were transitions. Alignments were compared by eye against the known structural conformation of the gene in Mytilus (Lydeard et al. 2000), which indicated that variable regions of the gene fragment predominated in loops and that the stem structures were highly conserved.

The phylogenetic relationship among sequences was inferred using the DNA parsimony algorithm in PAUP v 4.0 beta (Swofford 2002). For the specific protocol, change from an occupied site to a deletion is counted as one change; reversion from a deletion to an occupied site also counted as one change. Analyses included 51 sequences covering 36 Unionidae species and three Margeritiferidae species. Replicate sequences for each species were included only where intraspecific variation was detected.

To produce trees, three programs were used. First, a heuristic search based on parsimony produced 315 best trees. A strict consensus of these trees was produced. Second, the bootstrap protocol was run for 200 replications on the 51 sequences. If a group occurred in more than $50 \%$ of all the input trees it appeared in the consensus tree. Similar analyses used the Jackknife procedure, and the consensus tree produced was identical. The tree printed out has at each fork a number which indicates the percent of the time that the group consisted of all the species to the right of (descended from) the fork. Verification of results was obtained in a second analysis that examined the species of the Anodontinae and the Ambleminae alone because the large numbers of OTUs caused the program to produce numerous trees of equal length.

\section{RESULTS}

The total aligned data matrix (including indels, which could be either an insertion or a deletion) was $503 \mathrm{bp}$, of which 183 positions were parsimony informative. Based on these characters, a majority rule consensus parsimony tree (Fig. 2), which when run with 35 unionid species, indicated two wellsupported monophyletic groups, the traditionally described subfamilies: the Anodontinae, which includes the genera (Anodonta + Utterbackia + Pyganodon + Lasmigona + Alasmidonta + Anodontoides) and the Ambleminae. The Ambleminae was divisible into two previously defined monophyletic clades: the tribe, Pleurobemini which contains further well defined groups (Megalonaias nervosa + Quadrula quadrula,$+Q$. apiculata $+Q$. metanerva) and (Uniomerus obesus + Elliptio dilatata + Pleurobema pyriforme + Elliptoideus sloatianus + Fusconaia flava), each of which are strongly supported as monophyletic, and the larger tribe, Lampsilini (Lampsilis siliquoidea + L. teres + Ptychobranchus subtentum $+V$ illosa delumbis + Potamilus purpuratus + Ellipsaria lineolata + Leptodea fragilis + Medionidus conradicus ). The position of the genera Plectomerus, Obliquaria, Toxolasma, and Amblema may be a separate monophyletic group based on a neighbor-joining analysis (data not shown), but the evidence from this one gene is weak.

A strict consensus of the 315 equally parsimonious trees yielded similar results (Fig. 3), but it highlights a few potential discrepancies between a $16 \mathrm{~S}$ rRNA gene tree and the presently accepted phylogeny of unionid mussels. The two members of the genus Potamilus are no more different, and they may differ less, than do Lampsilis siliquoidea and $L$. radiata luteola from the congeneric species, $L$. teres. The addition of Toxolasma parvus, another member of the Lampsilini, to the tree proposed by Lydeard et al. (1996) strengthened a connection between the genera Obliquaria and Plectomerus. Plectomerus has traditionally been placed outside the Lampsilini based on characteristics of the marsupium, which is an outgrowth of the gills where embryos develop. Its inclusion would indicate developmental convergence of some marsupial characters (Lydeard et al. 1996).

\section{Intraspecific Variation}

Variation within species for the $5^{\prime}$ fragment of the $16 \mathrm{~S}$ rRNA gene was low. The only possible exception is for Quadrula quadrula. The individual from the Rocky River showed closer similarity to $Q$. apiculata (395 of $398 \mathrm{bp}$, or $>99 \%$ ) than it did to the southern specimen of Q. quadrula (381 of 398 bp, or $96 \%$ ) that was sequenced by Lydeard et al. (1996). Its identification was based on morphology and independently confirmed by $\mathrm{T}$. Watters (Ohio Biodiversity Museum) and M. Huehner (Hiram College, $\mathrm{OH})$. The 17 base differences present between the two sequences of $Q$. quadrula were significantly greater than the three variants present between individuals of Lampsilis teres (Table 1), which was the most differences found between any other individuals of the same unionid species (contingency test, $\mathrm{P}<0.01$ ).

Within NE Ohio, sequence diversity was very low. Only a pyrimidine transition occurred in the 


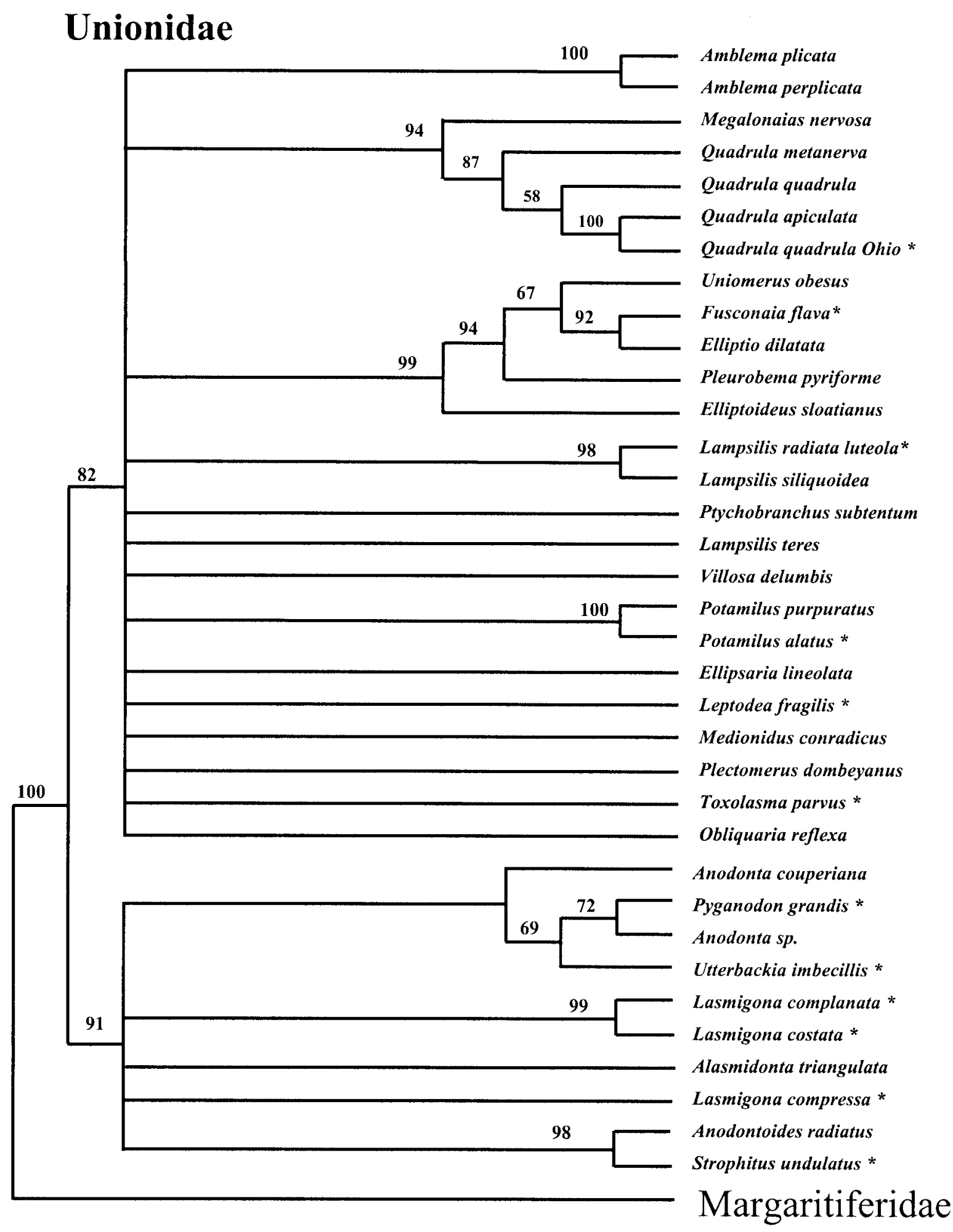

FIG. 2. A majority rule consensus tree for freshwater mussels with 200 replicate bootstrap run using a maximum parsimony analysis of the $16 \mathrm{~S}$ rRNA sequence data (Paup beta). The number at the nodes indicate the percentage of replications that a particular clade occurred in the bootstrap analysis. Asterisks indicate new taxa added to data from Lydeard et al. (1996). 


\section{Unionidae}

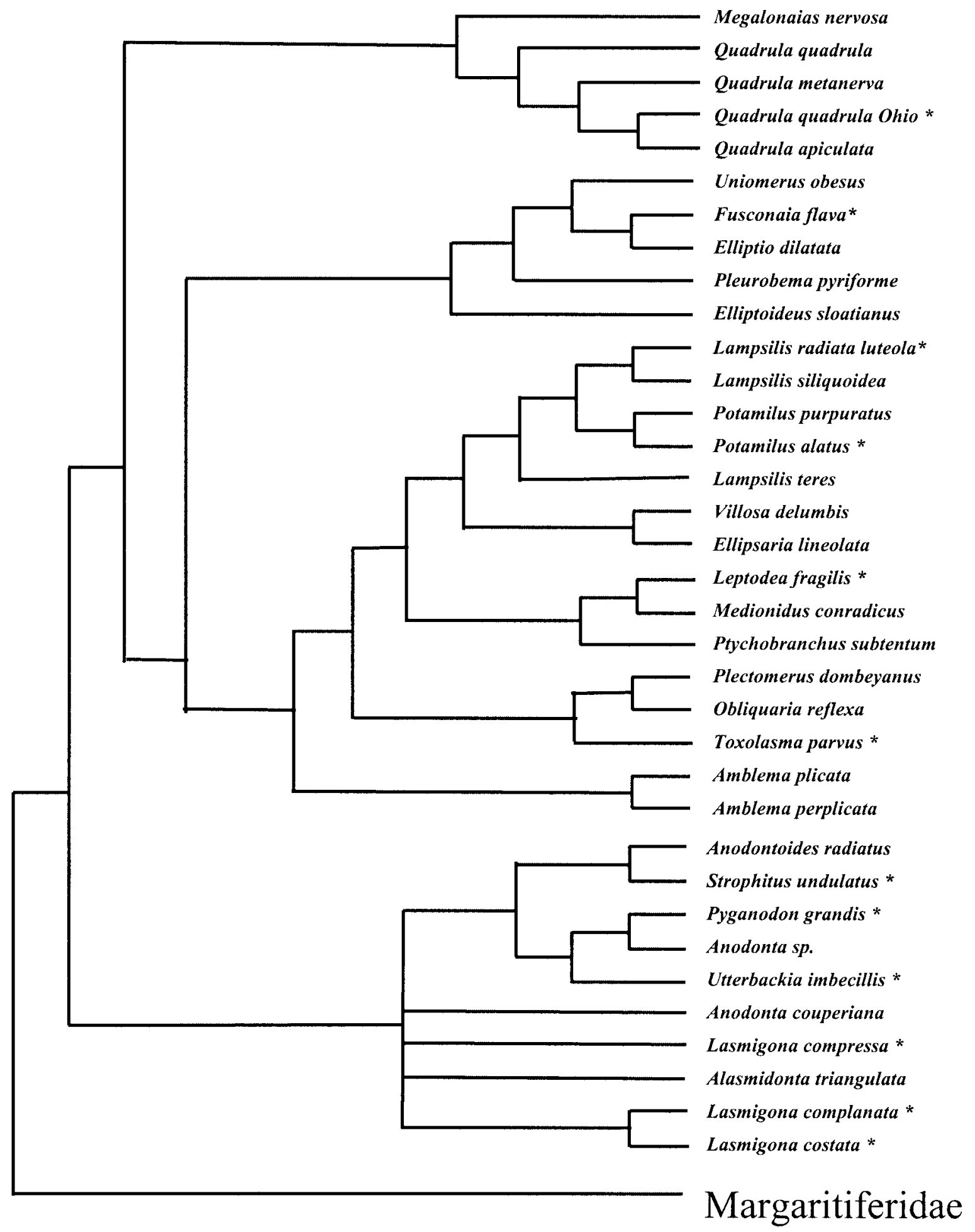

FIG. 3. A strict consensus of the 315 best trees found in a parsimony analysis of freshwater mussels using a heuristic maximum parsimony analysis of the $16 \mathrm{~S}$ rRNA sequence data (PAUP beta). The number at the nodes indicate that all replications of the best tree included that clade. Asterisks indicate new taxa added to data from Lydeard et al. (1996). 
TABLE 1. Intraspecific variation within unionid mussels based on DNA sequence of the proximal third of the $16 S$ rRNA gene of mitochondria [ $T s=$ transition, $K=$ current study, $L=L y d e a r d$ et al. (1996) study.

\begin{tabular}{|c|c|c|c|c|c|}
\hline Source & Species & $\mathrm{N}$ & Variant type & Position & $\%$ similarity \\
\hline $\mathrm{K}$ & Pyganodon grandis & 17 & $1 \mathrm{Ts}$ & 152 & $99.8 \%$ \\
\hline $\mathrm{K}$ & Lasmigona complanata & 2 & & & $100 \%$ \\
\hline $\mathrm{K}$ & L. compressa & 5 & $1 \mathrm{Ts}$ & 144 & $99.8 \%$ \\
\hline $\mathrm{K} \& \mathrm{~L}$ & L. costata & 7 & $1 \mathrm{Ts}$ & $185^{1}$ & $99.7 \%$ \\
\hline $\mathrm{K}$ & Lampsilis radiata luteola/siliquoidea & 5 & 1 indel & $61^{2}$ & $99.7 \%$ \\
\hline $\mathrm{L}$ & L. teres & 2 & 3 Ts & $57,239,303$ & $99.2 \%$ \\
\hline $\mathrm{K} \& \mathrm{~L}$ & Leptodea fragilis & 2 & 1 indel & 311 & $99.8 \%$ \\
\hline $\mathrm{K}$ & Fusconaia flava & 2 & & & $100 \%$ \\
\hline $\mathrm{K} \& \mathrm{~L}$ & Utterbackia imbecillis & 2 & & & $100 \%$ \\
\hline $\mathrm{L}$ & Quadrula apiculata & 2 & $1 \mathrm{Ts}$ & 195 & $99.7 \%$ \\
\hline
\end{tabular}

${ }^{1}$ Difference in one of the 2 sequences of Lydeard et al. (1996) only.

2 The sequence of Lydeard et al. (1996) named L. siliquoidea lacks one base present in all individuals of the present study.

486 bp gene fragment obtained for 17 Pyganodon grandis collected from these two watersheds. All Tinkers Creek individuals $(\mathrm{N}=7)$ and the two Rocky River specimens possessed the "T" haplotype, while seven of eight from the Cuyahoga mainstream and its connecting canal or ponds carried the $\mathrm{C}$ haplotype. The lone $\mathrm{T}$ haplotype was found in one of the four headwater individuals sequenced. Similarly, one difference was found in five sequences from Lasmigona compressa, another transition, but this time the two specimens from the Rocky River carried the haplotype found in the upper Cuyahoga, and the two Tinkers Creek individuals differed. No variants appeared in five sequences from Lasmigona costata, although one variant exists in one of the two L. costata sequences published by Lydeard et al. (1996). For the three $L$. radiata luteola specimens, and the two from each of F. flava and U. imbecillis, no variants were found. The published L. siliquoidea sequence differs from our L. radiata luteola sequences by a single-base indel; these species have previously been considered subspecies.

\section{DISCUSSION}

\section{Phylogenetic Implications}

Study of the phylogeny of North American unionids is ongoing because different systematic approaches and characters provide conflicting phylogenies (compare, for instance, the findings of Heard and Guckert 1971, Davis and Fuller 1981, and Lydeard et al. 1996). The phylogeny we present (Fig. 3) is one hypothesis, generated from a gene tree, that includes 25 different genera of the 48 gen- era described for 281 species in the Unionidae (Williams et al. 1993). Fifteen of the genera not included are monotypic. The phylogeny proposed, however, represents the "true" phylogeny of unionids only if patterns of change in this one gene fragment accurately reflect evolutionary events within the family. Nevertheless, most major branch points are supported by morphological characters (Lydeard et al. 1996) and our reevaluation and expansion of the $16 \mathrm{~S}$ rRNA data set enhanced the phylogeny that Lydeard et al. (1996) proposed. That is, despite the addition of numerous taxa, the major clades held up, and the consensus tree closely matched the strict consensus of the best trees they published previously. These results are gratifying because the addition of taxa, especially where the total number of characters is not large, can reduce support for deeper nodes in the phylogenetic tree (Huelsenbeck and Hillis 1993, Mitchell et al. 2000).

The 16S rRNA gene phylogeny continues to provide strong support for the subfamilies Anodontinae and Ambleminae, as well as for the tribes Pleurobemini and Lamsilini, described by Davis and Fuller (1981). One possible exception is the position of Obliquaria, which Lydeard et al. (1996) identified as a sister taxon to Plectomerus, and these appear to be close to Toxolasma. Both Obliquaria and Toxolasma are placed within the Lampsilini based on morphology (Lydeard et al. 1996). Therefore, our tree supports either inclusion of Plectomerus in the Lampsilini or the listing of Obliquaria, Plectomerus, Toxolasma, and Amblema and as a separate group either outside the Lampsilini or as a basal lineage within this tribe. As Heard and Guckert (1971) suggested, perhaps Plectomerus and Am- 
blema could be grouped under the tribe Amblemini, but unquestionably, more data are required.

\section{Conservation Implications}

Although the number of individuals sequenced in all but one species were very low, these results suggest that little intraspecific variation exists in the $16 \mathrm{~S}$ rRNA gene, even where individuals originate from different watersheds. Therefore, this fragment may be useful to identify long isolated populations or cryptic species. Two haplotypes separate $P$. grandis from Tinkers Creek and the main stem of the Cuyahoga River. None of the other species varied much, as the two L. costata that were collected from the Cuyahoga River system and a third from Rondout Creek in New York share one haplotype, while a fourth from the Finley River in Missouri varied in one site. Similarly, two distantly collected U. imbecillis, one from the Black River in South Carolina (Lydeard et al. 1996) and one from Kendall Lake, Ohio, are identical in sequence for the 16S rRNA. Hoeh et al. (1998) reported that this latter species is known for low levels of variation within a watershed, but they suggest it can be quite variable for allozymes between watersheds. The exception is for the two Q. quadrula individuals, which differed much more, highlighting a need for additional sampling in this group.

Little variation between sibling species mirrors results on variation among individuals from different watersheds. Lampsilis radiata luteola (Watters 1995), which is sometimes considered Lampsilis siliquoidea outside Ohio, differs from the published L. siliquoidea sequence by one indel early in the sequence. Likewise Amblema plicata differs in a single site from $A$. perplicata, a close relative from the coast along the Gulf of Mexico, and these two taxa vary in their designation as species or subspecies (Williams et al. 1993, Mulvey et al. 1997).

Given the sound phylogeny developing above the generic level, sequence data for freshwater mussels provides a quantitative measure of biological diversity. As many as 15 species may occur in the Cuyahoga River and Rocky River watersheds, of which sequences were produced for twelve. Of the others, a number are not sufficiently common to predictably collect (i.e., A. ferussacianus and $A$. marginata) or the taxa receive state protection prohibiting collection ( $L$. nasuta). Species belonging to all of the major unionid groups are present. Lampsilis radiata luteola and Potamilus alatus represent the Lampsilini, Fusconaia flava and
Quadrula quadrula represent the two putative branches of Pleurobemini, and Toxolasma parvus separates basally in the Ambleminae.

The relationship between biological and genetic diversity is identified by the levels of variation within the various taxa. In the Pleuroblemini, which contains several basally divergent lineages, $28 \%$ of sites are polymorphic, in the Lampsilini (including Plectomerus), this proportion is only $10 \%$, while in the Anodontini, $27 \%$ of sites vary. Considering data for all of the available unionid species, $45 \%$ of sites varied, and the level of variation within individuals from these two small rivers is $34 \%$ of the $505 \mathrm{bp}$ of the $16 \mathrm{~S}$ rRNA sequenced.

Of concern, however, is that the majority of the individuals found in the watershed (Pyganodon grandis, Utterbackia imbecillis, Lasmigona costata, and Lasmigona compressa) (Smith et al. 2002), belong to the subfamily Anodontinae, and the abundance of these taxa appears to be increasing (Tevesz et al. 2002). Similar trends occur in the Canadian streams on the north side of Lake Erie, which Metcalfe-Smith et al. $(1998,2000)$ address as a specific problem. They report that many of these species are more tolerant of exposed rivers, and therefore indicate change in habitat, such as a loss of Riparian zones. A specific example is the replacement of Lampsilis siliquoidea by Pyganodon grandis as the dominant species, and this change is mirrored by differences in shell versus live animal collections for L. radiata luteola and $P$. grandis in Tinkers Creek (Krebs et al. 2002), the largest tributary of the Cuyahoga. Such conditions may be a prelude to the loss of species from a watershed.

These changes therefore should raise an alarm that while the present species illustrate a phylogenetically diverse unionid fauna within the streams that flow through the urban/suburban Cleveland region, any further degradation of the habitat may result in large changes to the biota. Enough similarities are beginning to appear between research in Canada and the U.S. to guide local conservation efforts towards preserving the genetic make-up of mussel populations in and around Lake Erie. Although none of the species analyzed in this study are listed as endangered or threatened at a federal level, and only Ligumia nasuta is state listed, our surveys suggest several may be locally threatened. Potamilus alatus is known from only two specimens and a few shells in the Cuyahoga (Smith 2000, Smith et al. 2002), and Quadrula from only a single specimen. In the Rocky River (Krebs, data unpublished), P. alatus is present only 
near the mouth of the river, and Q. quadrula from a single old (length $=131 \mathrm{~mm}$ ) individual washed up on the riverbank. This detailed phylogeny indicates that only members of the Anodontinae are both abundant and dispersed throughout the watershed. Therefore, different indices of diversity may vary vastly in how this watershed is categorized, and small changes in abundance could rapidly alter any diversity index applied to the watershed based simply on species presence.

\section{ACKNOWLEDGMENTS}

We thank the administrators of the Cuyahoga Valley National Park and the Ohio Division of Natural Resources for permission to collect mussels (Federal permit \#: CUVA-00-004; State permit \#288. Angel Fasolo assisted with the initial development of protocols, Bryan Child sequenced the Rocky River material, and members of the Ohio Underwater Research Association and Biological, Geological and Environmental Sciences Department colleagues Ralph Gibson and Michael Gates helped collect specimens for the project. Finally, we thank Charles Lydeard for reviewing the manuscript. The work was supported in part by an NSF small grant for exploratory research (DEB0002305), by a fellowship from the Program for Excellence in Risk Analysis in the Center for Environmental Science, Technology and Policy, CSU, to RAK, and by a supplemental EFFRD award to MJST.

\section{REFERENCES}

Boore, J.L. 1999. Animal mitochondrial genomes. Nucleic Acid Res. 27:1767-1780.

Canapa, A., Barucca, M., Marinelli, A., and Olmo, E. 2000. Molecular data from the 16S rRNA gene for the phylogeny of Pectinidae (Mollusca: Bivalvia). $J$. Molec. Evol. 50:93-97.

Davis, G.M., and Fuller, S.L.H. 1981. Genetic relationships among recent Unionacea (Bivalvia) of North America. Malacologia 20:217-253.

Heard, W.H., and Guckert, R.H. 1971. A re-evaluation of the recent Unionacea (Pelecypoda) of North America. Malacologia 10:333-355.

Hillis, D.M., Mable, B.K., and Moritz, C.M. 1996. Applications of molecular systematics. In Molecular Systematics, eds. D.M. Hillis, C.M. Moritz, and B.K. Mable, pp. 535-553, Sunderland, MA: Sinaur.

Hoeh, W.R., Stewart, D.T., Sutherland, B.W., and Zouros, E. 1996. Multiple origins of gender-associated mitochondrial DNA lineages in bivalves (Mollusca: Bivalvia). Evolution 50:2276-2286.
Frazer, K.S., Naranjo-Garcia, E., Black, M.B., Berg, D.J., and Guttman, S.I. 1998. Correlation between mating system and distribution of genetic variation in Utterbackia (Bivalvia: Unionidae). $J$. Shellfish Res. 17:1383-1393.

Huelsenbeck, J.P., and Hillis, D.M. 1993. Success of phylogenetic methods in the 4-taxon case. Syst. Biol. 42:247-264.

Krebs, R.A., Griffith, H.M., and Tevesz, M.J.S. 2002. A study of the Unionidae of Tinkers Creek Ohio. Kirtlandia 53:19-25.

Ladoukakis, E.D., and Zouros, E. 2001. Direct evidence for homologous recombination in mussel (Mytilus galloprovincialis) mitochondrial DNA. Molec. Biol. Evol. 18:1168-1175.

La Rocque, A. 1967. Pleistocene Mollusca of Ohio. Ohio Geological Survey, Bulletin No. 2.

Liu, H., Mitton, J.B., and Wu, S. 1996. Paternal mitochondrial DNA differentiation far exceeds maternal mitochondrial DNA and allozyme differentiation in the freshwater mussel, Anodonta grandis grandis . Evolution 50:952-957.

Lydeard, C., and Roe, K.J. 1998. Phylogenetic systematics: The missing ingredient in the conservation of freshwater unionid bivalves. Fisheries 23:16-17.

Mulvey, M., and Davis, G. 1996. Molecular systematics and evolution of reproductive traits of North American freshwater unionacean mussels (Mollusca: Bivalvia) as inferred from 16S rRNA gene sequences. Phil. Trans.Roy. Soc. London B 351:1593-1603.

Yoder, J.H., Holznagel, W.E., Thompson, F.G., and Hartfield, P. 1998. Phylogenetic utility of the 5'half of mitochondrial 16S rDNA gene sequences for inferring relationships of Elimia (Cerithioidea : Pleuroceridae). Malacologia 39:183-193.

Holznagel, W.E., Schnare, M.E., and Gutell, R.R. 2000. Phylogenetic analysis of molluscan mitochondrial LSU rDNA sequences and secondary structures. Mol. Phylo. Evol. 15:83-102.

Metcalfe-Smith, J.L., Staton, S.K., Mackie, G.L., and Lane, N.M. 1998. Changes in the biodiversity of freshwater mussels in the Canadian waters of the lower Great Lakes drainage basin over the past 140 years. J. Great Lakes Res. 24:845-858.

Mackie, G.L., Di Maio, J., and Staton, S.K. 2000. Changes over time in the diversity and distribution of freshwater mussels (Unionidae) in the Grand River, southwestern Ontario. J. Great Lakes Res. 26:445-459.

Mitchell, A., Mitter, C., and Regier, J.C. 2000. More taxa or more characters revisited: Combining data from nuclear protein-encoding genes for phylogenetic analyses of Noctuoidea (Insecta : Lepidoptera). Syst. Biol. 49:202-224.

Mulvey, M., Lydeard, C., Pyer, D.L., Hicks, M., BrimBox, J., Williams, J.D., and Butler, R.S. 1997. Conservation genetics of North American freshwater mus- 
sels Amblema and Megalonaias. Conserv. Genet. 11:868-878.

, Liu, H.-P., and Kandl, K.L. 1998. Application of molecular genetic markers to conservation of freshwater bivalves. J. Shellfish Res. 17:1395-1405.

Palumbi, S.R. 1997. Nucleic acids II: The polymerase chain reaction. In Molecular Systematics, $2^{\text {nd }}$ Ed., eds. D.M. Hillis, C. Moritz, B.K. Mable, pp. 205-247, Washington D.C.: Sinauer.

Skibinski, D.O.F., Gallagher, C., and Quesada, H. 1999. On the roles of selection, mutation, and drift in the evolution of mitochondrial DNA diversity in British Mytilus edulis (Mytilidae; Mollusca) populations. Biol. J. Linn. Soc. 68:195-213.

Smith, D.C. 2000. A survey of freshwater molluscs in the Cuyahoga Valley National Recreation Area. M. S. thesis, Cleveland State University, Cleveland, OH.

, Gates, M.A., Krebs, R.A., and Tevesz, M.J.S. 2002. A survey of freshwater mussels (Unionidae) and other molluscs in the Cuyahoga Valley National Park. Ohio Biological Survey, Miscellaneous Contribution No. 8.

Stein, B.A., and Flack, S.R. 1997. 1997 species report card: the state of U.S. plants and animals. Arlington, VA: The Nature Conservancy.

Stepien, C.A., Hubers, A.N., and Skidmore, J.L. 1999. Diagnostic genetic markers and evolutionary relation- ships among invasive dreissenoid and corbiculoid bivalves in North America: phylogenetic signal from, mitochondrial 16S rDNA. Mol. Phylo. Evol. 13:31-49.

Swofford, D.L. 2002. PAUP*. Phylogenetic Analysis Using Parsimony (*and Other Methods) Version 4. Sinauer Associates, Sunderland, Massachusetts.

Tevesz, M.J.S., and Carter, J.G. 1980. Environmental relationships of shell form and structure of Unionacean bivalves. In Skeletal Growth of Aquatic Organisms, D. C. Rhoads and R. A. Lutz (eds), pp. 295-322, Plenum Publ.

, Rundo, L., Krebs, R.A., Redman, B.G., and DuFresne, A.S. 2002. Changes in the freshwater mussel (Bivalvia: Unionidae) fauna of the Cuyahoga River, Ohio, since late prehistory. Kirtlandia 53:13-18.

Watters, G.T. 1995. A Guide to the Freshwater Mussels of Ohio, 3rd ed. The Ohio Division of Wildlife. Columbus, Ohio.

Williams, J.D., Warren, M.L., Jr., Cummings, K.S., Harris, J.L., and Neeves, R.J. 1993. Conservation status of the freshwater mussels of the United States and Canada. Fisheries 18:6-22. 